\title{
CONVERGÊNCIA E SIGNOS NO PROCESSO SELETIVO DE UMA INSTITUIÇÃO PÚBLICA EDUCACIONAL
}

\section{Convergence and signs in the selection process of an educational institution public}

Convergencia y señales en el proceso de selección de una institución educativa pública

\author{
Susana Nunes Taulé Piñol ${ }^{1}$ \\ Ana Beatriz de Lara $^{2}$
}

\section{Resumo}

Este estudo apresenta, sob a ótica dos estudantes, os signos e as convergências presentes no processo de escolha da instituição pública educacional como organização responsável pela sua formação. Fatores e sentimentos são revelados pela adoção do método qualitativo proposto por Gerald Zaltman (2003) no ambiente educacional. Identificando metáforas, os resultados mostram a complexidade do processo decisório destes jovens consumidores.

Palavras-chave: escola, seleção, marketing.

\begin{abstract}
This study presents the perspective of students, signs and convergences present in the process of choosing a public educational institution as an organization responsible for its formation. Factors and feelings are revealed by the adoption of qualitative method proposed by Gerald Zaltman (2003) in the educational environment. Identifying metaphors, the results show the complexity of the decision-making process of these young consumers.
\end{abstract}

Keywords: school, selection, marketing.

\section{Resumen}

Este estudio presenta la perspectiva de los estudiantes, los signos y las convergencias existentes en el proceso de elegir una institución educativa pública como una organización

\footnotetext{
${ }^{1}$ Mestre em Administração pela Universidade Federal de Santa Catarina - UFSC e Bacharel em Administração pela Universidade Federal do Rio Grande do Sul - UFRGS, atualmente coordena a Pesquisa e a Extensão do - IFMT Campus Rondonópolis. Telefone: (66) 34272300. E-mail: susana.pinol@roo.ifmt.edu.br.

${ }^{2}$ Acadêmica do Curso Técnico Integrado ao Ensino Médio em Química - IFMT Campus Rondonópolis. Bolsista do CNPq. Telefone: (66) 34272300. E-mail: laranabeatriz10@ hotmail.com.
} 
Convergência e signos no processo seletivo de uma instituição pública educacional

de Susana Nunes Taulé Piñol e Ana Beatriz de Lara

responsable de su formación. Factores y sentimientos son revelados por la adopción de un método cualitativo propuesto por Gerald Zaltman (2003) en el ámbito educativo. Identificando las metáforas, los resultados muestran la complejidad del proceso de toma de decisiones de estos consumidores jóvenes.

Palabras-clave: escuela, selección, marketing.

\section{INTRODUÇÃO}

Os seres humanos são seres complexos e interagem com um ambiente cada vez mais complexo. Entretanto não consomem como os animais, "porque nossa relação com nossas necessidades e nosso meio ambiente não é instintiva, nem programada, nem limitada à sobrevivência física do indivíduo ou da espécie” como pondera Slater (2002: 130). Compreender as necessidades humanas e a forma como este ser articula as inúmeras informações que participam de seu processo decisório é algo no mínimo intrigante.

O período normalmente mais denso de indefinições é a adolescência, o jovem que está se tornando adulto precisa escolher "o que vai ser quando crescer?". A seleção da instituição educacional que conduzirá a sua formação é um processo integrante desta definição.

O adolescente, de um modo geral, comparado à boa parte dos adultos, é hoje um hábil usuário das novas tecnologias. Situação que os inseri, mesmo os mais tímidos, nos diferentes processos comunicativos digitais. Contudo, não é apenas as informações disponíveis nos veículos de comunicação, digitais ou não, que interferem no processo decisório sobre qual instituição educacional estudar, há muitos outros fatores materiais e imateriais presentes.

A proposta deste estudo é desvendar os sentimentos vivenciados pelos estudantes na trajetória que perpassa o antes, durante e depois da seleção de uma escola pública como organização responsável pela sua formação. Especificamente, reconhecendo as metáforas presentes neste processo e identificando sentimentos e fatores influenciadores.

Propositalmente, com o intuito de descartar a interferência do valor da mensalidade, elegeu-se uma escola pública como foco deste estudo. E uma escola que integrasse ensino médio ao ensino técnico, reunindo desta forma a necessidade de decisão do ainda jovem a uma perspectiva de formação profissional necessariamente definida no momento da inscrição no processo seletivo da instituição em tela. Com estas delimitações buscou-se apurar a essência deste processo sob a ótica do estudante. 


\section{BASE CONCEITUAL}

O ser humano é movido a reações o tempo todo e tudo o que faz em sua vida gera um sentimento. Sentimentos são informações que todos os seres biológicos são capazes de sentir nas diferentes situações que vivenciam e que podem afetar suas decisões. Para Engel, Blacwell e Miniard (2000: 240) "tanto o componente cognitivo (crenças) quanto o componente afetivo (sentimentos) estão conceitualizados como determinantes das atitudes".

As atitudes podem ser bastante úteis para compreender o porquê de uma determinada escolha. No caso de selecionar uma escola, há vários sentimentos envolvidos como a mudança de rotina, o medo do desconhecido, de ser rejeitado, de não fazer amizades, de não se adaptar; principalmente em escolas que usam de processos seletivos para eleger seus alunos.

Nestas situações, só ingressa na escola quem se esforça o suficiente. Portanto, o medo, a ansiedade, a curiosidade e outros adjetivos podem aflorar ainda mais nos candidatos. Mais que sentimentos, o processo de escolha do consumidor é composto por diferentes etapas, como relatam Kotler e Fox (1994).

A provocação da necessidade de se formar naquela escola pode ser alimentada por informações presentes em mala direta; notícias e relações públicas; propagandas; eventos; orientação educacional; opiniões de pais e de colegas. A coleta de informações sobre a escola pode ser obtida em publicações da escola, visita às instalações e websites servindo como base para a próxima etapa de avaliação de decisão.

No momento em que as alternativas de decisão são avaliadas a reputação, o currículo, o corpo docente, as instalações, a localização, o custo da anuidade, o tamanho da escola e outros atributos podem ser relevantes. E na execução da decisão a assistência ao aluno e informações adicionais podem colaborar no processo decisório. Na avaliação pós decisão o aluno pode ainda considerar publicações; informações por telefone; mala direta; feiras de divulgação e recrutamento (KOTLER e FOX, 1994).

Muitos fatores interferem na escolha do jovem sobre qual instituição eleger e muitas pessoas exercem papéis diferentes ao longo deste processo influenciando, acompanhando e avaliando partes deste processo. Engel, Blacwell e Miniard (2000: 464) ressaltam a influência da expressão de valor pelo grupo de referência. 
Os grupos de referência também podem desempenhar uma função de expressão de valor, em que uma necessidade de associação psicológica com um grupo é evidenciada por aceitação de suas normas, valores ou comportamentos, e é dada uma resposta adequada, muito embora possa não haver motivação para tornar-se um membro. Um resultado desejado é realçar sua própria imagem aos olhos de outros. Uma outra é a identificação com pessoas que são admiradas e respeitadas.

O aluno é aquele que estará em contato direto com a instituição educacional sofrendo os efeitos diretos desta relação antes, durante e depois do processo. Os pais tem interferência mais ampliada ou mais reduzida no processo decisório conforme a faixa etária do aluno. O perfil da família também interfere neste contexto, assim como experiências anteriores. Uma família que já residiu em outras localidades e que teve experiências com outras instituições educacionais tende a ser mais crítica e a considerar mais critérios em comparação a outros grupos familiares.

\section{MÉTODO DE PESQUISA}

O método proposto por Gerald Zaltman foi adotado de forma adaptada com o intuito de apurar as metáforas presentes no processo desencadeado sob a ótica do jovem estudante. A construção de desenhos, também conceituada por Vergara (2006) é o start up do método. "Esta técnica visa estimular a manifestação de dimensões emocionais, psicológicas e políticas pouco privilegiadas por técnicas de cunho racional."

De acordo com Zaltman (2003: 178),

[...] quanto mais fundo sondamos os pensamentos e os sentimentos dos consumidores sobre situações e contextos comuns entre eles, maior será a probabilidade de que encontremos constructos importantes também compartilhados [...] Não só diferentes consumidores compartilham muitos dos mesmos pensamentos e sentimentos profundos sobre necessidades de produtos, serviços ou experiências, como também as maneiras como esses constructos se relacionam uns com os outros são comuns entre pessoas sob outros aspectos diferentes.

O principal motivo do emprego desta técnica é ir além das palavras, enfatizando a emoção. Como relata Zaltman (2003: 70), “a parceria emoção-razão é em si um argumento para a adoção de métodos de pesquisa que permitam o afloramento tanto da razão quanto da emoção e que reflitam sua coexistência e influência recíproca."

Nas imagens as relações sintagmáticas são espaciais e não temporais. A construção de desenhos motiva o entrevistado a utilizar metáforas, estas, por sua vez, trazem à tona pensamentos e sentimentos ainda que inconscientes. As experiências inconscientes são 
trazidas para o nível da consciência e em seguida transmitidas aos outros (ZALTMAN, 2003: 68).

O processo de análise semiológica consiste na dissecação seguida pela articulação, ou pela reconstrução da imagem semantizada, perpassando por uma validação comunicativa registrada por entrevistas em profundidade. Este processo é o mais indicado nestes casos, e o eleito para este estudo. A semiologia pode ser combinada com alguma forma interativa dos dados e o trabalho do entrevistador é focar a atenção dos participantes no material, sem conduzir suas respostas.

A população designada foi alunos ingressantes de uma escola da rede pública federal que oferta cursos técnicos integrados ao ensino médio. E a amostragem foi probabilística considerando curso e gênero, adotando-se a fórmula de população finita proposta por Mattar (1996). Para o cálculo do tamanho da amostra admitiu-se a probabilidade de ocorrência e de não ocorrência de 50\%, um nível de confiabilidade de $95 \%$ e erro não amostral de 0,05 .

Fig. 1- Fórmula população finita de Mattar

$\begin{array}{ll}\text { População Finita } & \mathrm{n}=\frac{\mathrm{NZ}^{2} \mathrm{PQ}}{\mathrm{e}^{2}(\mathrm{~N}-1)+\mathrm{Z}^{2} \mathrm{PQ}} \\ \text { Legenda } & \\ \mathrm{n}=\text { Tamanho da Amostra } & \mathrm{P}=\text { Probabilidade de Ocorrência } \\ \mathrm{N}=\text { Tamanho da População } & \mathrm{Q}=\text { Probabilidade de Não Ocorrência } \\ \begin{array}{l}\mathrm{Z}=\text { Pontos da curva normal } \\ \text { relacionada com o Desvio Padrão }\end{array} & \mathrm{e}=\text { Erro não amostral }\end{array}$

Por meio de sorteio onde todos tiveram chance igual e diferente de zero de participar, foram selecionados 16 entrevistados respeitando a equidade de gênero e curso.

Para a construção do desenho foi solicitado ao participante que em uma folha em branco, contendo apenas instruções, este desenhasse uma imagem sem texto que refletisse o processo de escolha pela escola. Ao mesmo era permitido usar colagens ou mesclar colagens e desenhos, conforme preferência. Conforme Vergara (2006), neste caso, a coleta pode ser definida como não estruturada porque, embora sob uma única temática, cada sujeito teve a liberdade para escolher o que desenhar. 
Após a construção de desenhos, sucederam-se mais duas etapas de coleta. Inicialmente foi solicitado ao participante que registrasse de cinco a dez palavras ou frases no verso da folha do desenho que poderiam ser associadas à imagem gerada. Em seguida procedeu-se a etapa de gravação da entrevista onde cada participante emitiu seu depoimento acerca do significado do desenho. Em todas as etapas foi garantido o anonimato do entrevistado.

\section{ANÁLISE E DISCUSSÃO DOS RESULTADOS}

Os desenhos dos entrevistados serviram de base para análise sendo amparados pelos depoimentos dos entrevistados. Dois quadros apresentam os principais sentimentos e os fatores que interferem no processo de escolha da escola, sendo estes quadros uma representação prática de toda a análise.

Fig. 2- Desenho integral de um entrevistado

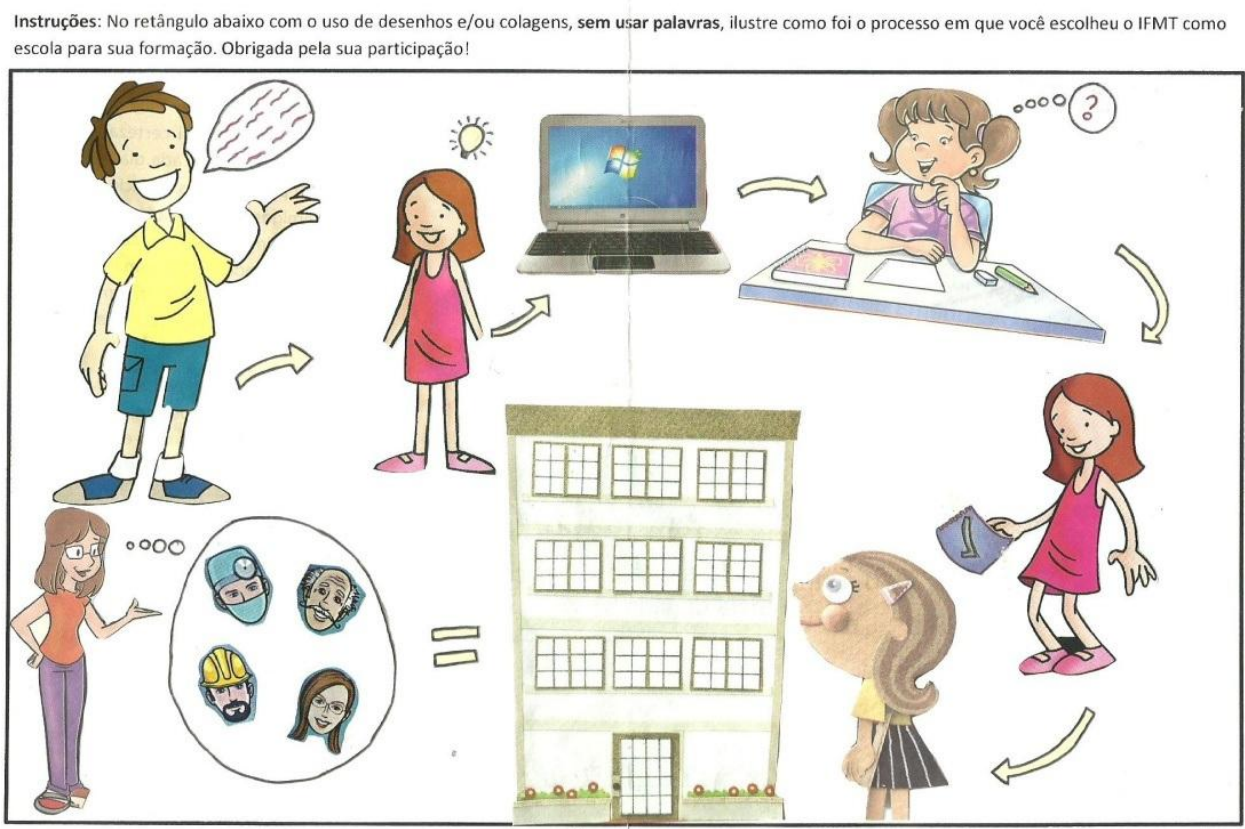

Nos quadros de análise é possível associar a metáfora aos sentimentos e fatores apresentados pelos entrevistados mediante depoimentos de correlação. 
No primeiro quadro ilustrado são apresentados os sentimentos detectados pelos alunos durante o processo de escolha da escola.

Fig. 3- Quadro de análise de sentimentos

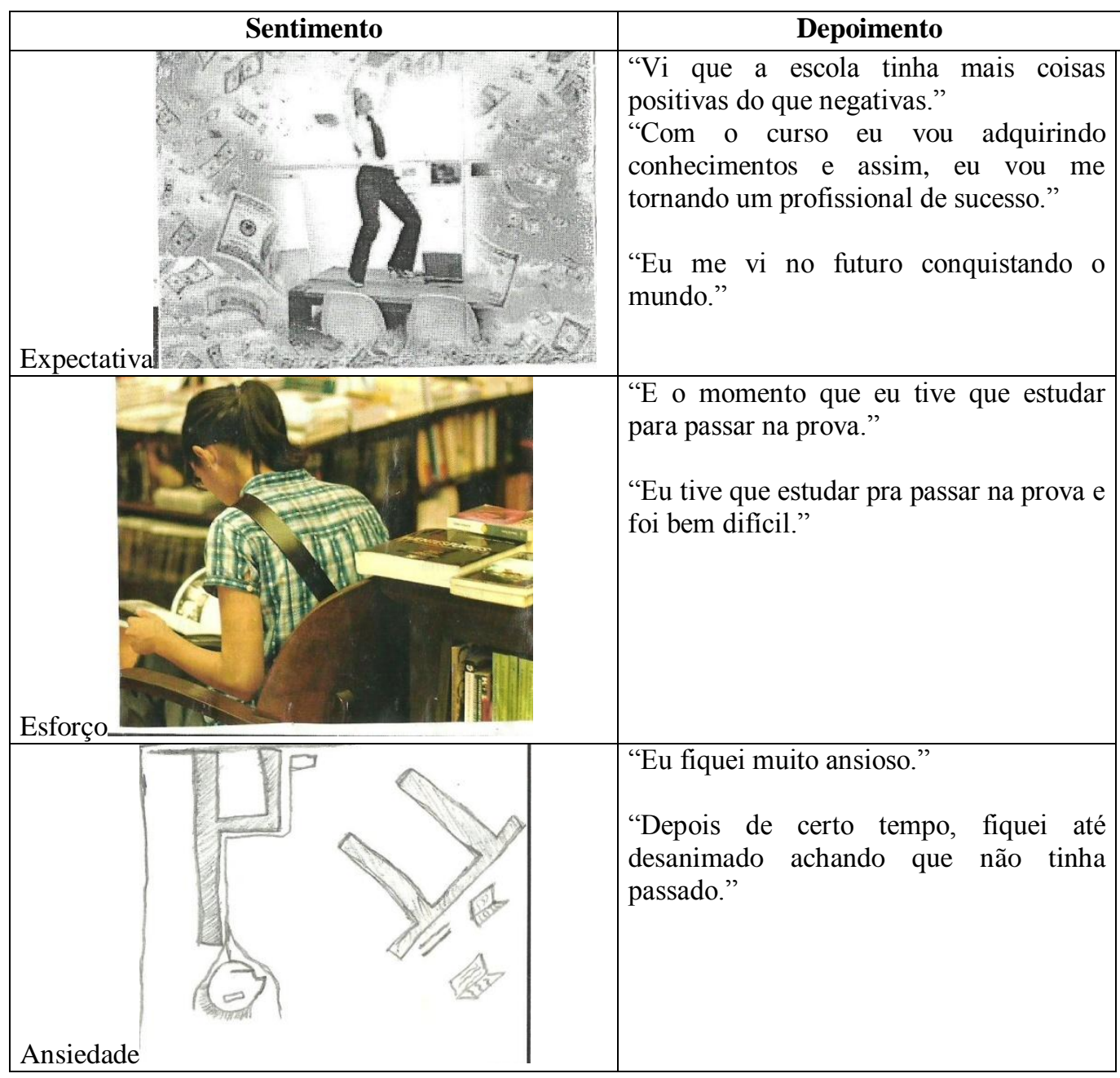

No quadro de análise de sentimentos é possível constatar a expectativa de sucesso apresentada pela metáfora do dinheiro como imagem ou de referência ao cifrão (\$), bem como, os braços erguidos reticentes em vários desenhos coletados junto aos entrevistados aludindo à vitória ou a ser vencedor. Neste ponto detecta-se o processamento de lembrança induzida por crença, “de cima para baixo” conforme definição de Zaltman (2003: 242), “o esquema geral é fundamental para orientar a interpretação da nova experiência, de modo a confirmar convicções e especificar ações compatíveis com tais convicções”.

$\mathrm{O}$ esforço diante da prova seletiva comunga com esta abordagem sendo um sentimento presente na imagem que aproxima o candidato dos livros na ação de estudar 
Convergência e signos no processo seletivo de uma instituição pública educacional

de Susana Nunes Taulé Piñol e Ana Beatriz de Lara

muito. Se eu acredito que esta nova experiência proporcionará um futuro promissor, a ação de esforço para estudar é compatível com esta convicção. Engel, Blackwell e Miniard (2000) categorizam a persistência como uma das propriedades da atitude. O candidato se esforça para ingressar na escola e esta ação pode gradualmente se desgastar devido à passagem do tempo, estando associada à preparação para o processo seletivo da instituição.

A ansiedade é outro sentimento presente nos jovens que participam desta experiência, sentimento também associado à confiança ou à falta de confiança que representa a crença de uma pessoa em relação a sua atitude estar correta. Este sentimento, bastante comum na adolescência é representado por imagens de dúvida ou mesmo de “jogar tudo para cima”.

De fato, nas empresas é detectado que equipes formadas por jovens compostas por representantes da Geração Y (nascidos a partir de 1980) requerem retornos rápidos pelo seu desempenho, ficando desmotivados quando isto não ocorre no tempo esperado.

Os jovens da geração $Y$ se desenvolveram em um contexto, no qual tudo está relacionado com o verbo compartilhar, desde sites até livros, de conteúdos relevantes a opiniões bem pessoais. E esse compartilhamento acontece na velocidade de um clique.[...] esses jovens não conseguem compreender o porquê das coisas não ocorrem da mesma maneira com a mesma rapidez. (ESTEVES, 2012)

Em uma visão mais abrangente é possível perceber que o sacrifício está presente nesta correlação. Se eu ingresso em um processo que merece meu esforço e que me gera ansiedade é porque, de certa forma acredito que serei vencedor, que terei sucesso. No entanto, como aborda Miller (2002), há somente insinuações sem aprofundamentos na literatura comparada no que tange a relação sacrifico-consumo. Por outro lado, a ênfase na educação e na busca pelo conhecimento como mecanismo de ascensão social nunca esteve tão evidente junto à massa consumidora.

$\mathrm{O}$ segundo quadro de análise apresenta os fatores presentes neste processo. $\mathrm{O}$ incentivo dos pais, a opinião de amigos e familiares, a divulgação da instituição nas escolas na ocasião de abertura do processo seletivo, o panfleto, o website (computador) e propagandas institucionais aparecem como fatores influenciadores.

Fig. 4- Quadro de análise de fatores 


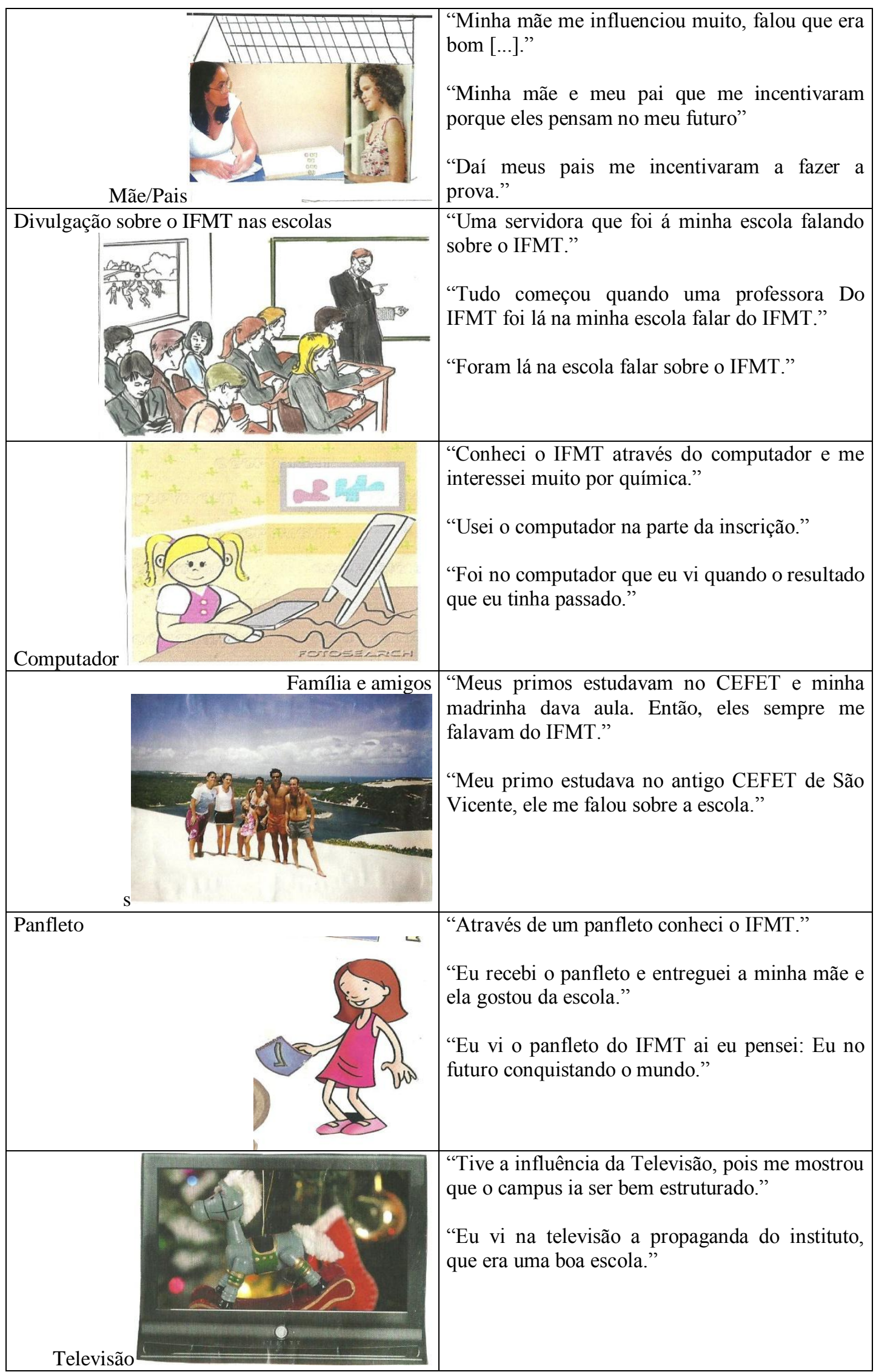


Neste quadro é perceptível que fatores humanos e materiais colaboram no processo decisório. Sendo a família o fator de maior interferência neste processo. Como relatam Engel, Blackwell e Miniard (2000: 478) a família reflete as atividades e influências dos indivíduos na família.

\begin{abstract}
Três variáveis ajudam a explicar como as famílias funcionam incluem coesão, adaptabilidade e comunicação. [...] Comunicação é uma dimensão facilitadora, crucial para o movimento nas outras duas dimensões. Habilidades de comunicação positivas (como empatia, ouvir com atenção e consideração, comentários de apoio) capacitam os membros da família a partilhar suas necessidades e preferências na medida em que se relacionam a coesão e adaptabilidade.
\end{abstract}

No caso de famílias e amigos a interferência humana tem dois desdobramentos, um relacionado à influência do boca a boca em que os consumidores frequentemente procuram outros, especialmente amigos e membros da família, para opiniões sobre produtos e serviços; e outro relacionado à expressão de valor do grupo de referência, como expressão da própria imagem aos olhos de outros ou como identificação a pessoas admiradas e respeitadas, além do sentimento de pertença.

A mãe em especial é a mais citada como fator interferente. É a chefa de família que atua aqui como principal influenciadora do processo decisório quando não em parceria com o pai. Elucidando um ponto comum, em nível profundo, o vínculo mãe-filho.

A convergência de diferentes canais on-line e off-line também pode ser constatada no quadro de análise, assim como o contato pessoal e impessoal. Se em primeira instância a visita de um servidor da escola divulgando o processo seletivo é um fator que desperta ou confirma o interesse pela instituição, em um segundo momento é o panfleto que leva a informação mais detalha e é a Internet, seja pela visita no website institucional ou na visita a redes sociais, que nutrem o processo com diferentes opiniões.

Neste ponto, o processamento de lembranças induzidas por conhecimentos ocorre "de baixo para cima", conforme Zaltman (2003: 242) "as novas experiências são fundamentais para forçar a reunião de informações adicionais que construam ou modifiquem esquemas de memória."

Sobre convergência de canais Wind, Mahajan e Gunther (2003: 112) reforçam a importância de criar interações sem descontinuidade com os públicos da organização por meio de canais on-line e off-line. "O poder da Internet não tem relação com transações que iniciam e terminam on-line, mas com interações com o cliente que passam por canais múltiplos, de on-line para off-line e em sentido inverso". 


\section{CONSIDERAÇÕES FINAIS}

Este estudo apontou como sentimentos presentes no jovem que escolhe uma instituição pública educacional federal que integra o ensino médio ao ensino técnico: o esforço, a ansiedade e a expectativa de conquista de um futuro promissor.

As interferências humanas principais neste processo são efetivadas pelos pais, familiares e amigos; e as interferências ambientais mais significativas no período que antecede o ingresso são: a visita dos servidores às escolas na ocasião de divulgação do processo seletivo, o panfleto informativo, a propaganda na televisão e as informações disponíveis na Internet.

Como metáfora profunda este estudo identificou que os estudantes veem a instituição educacional eleita como merecedora de seu esforço e uma organização que lhes fornecerá conhecimento suficiente para que possam ter êxito na sociedade.

Este estudo não tem caráter conclusivo, mas acredita-se que, para aprofundamento do tema, novos estudos sobre canais de convergência com foco em ações de atualização constante no website institucional e de relacionamento da instituição educacional com o público e a família são pertinentes, bem como estudos que avaliem a aproximação da instituição com as redes sociais.

\section{REFERÊNCIAS BIBLIOGRÁFICAS}

ENGEL, J.F.; BLACKWELL, R.D. e MINIARD, P.W. Comportamento do consumidor. 8.ed. Rio de Janeiro: LTC, 2000.

ESTEVES, S. “Como devo gerenciar a ansiedade dos jovens?” in Grupo Soma, São Paulo, 20/11/2012. Disponível em: http://www.gruposoma.net/Como-devo-gerenciar-aansiedade-dos-jovens. Acesso em: 20/11/2012.

KOTLER, P. e FOX, K.F.A. Marketing estratégico para instituições educacionais. São Paulo: Atlas, 1994.

MILLER, D. Teoria das compras: o que orienta as escolhas dos consumidores. São Paulo: Nobel, 2002.

SLATER, D. Cultura do consumo \& modernidade. São Paulo: Nobel, 2002.

VERGARA, S.C. Métodos de pesquisa em administração. 2. Ed. São Paulo: Atlas, 2006. 
Convergência e signos no processo seletivo de uma instituição pública educacional de Susana Nunes Taulé Piñol e Ana Beatriz de Lara

WIND, Y.J., MAHAJAN, V. e GUNTHER, R.E. Marketing de convergência: estratégias para conquistar o novo consumidor. São Paulo: Pearson Education do Brasil, 2003.

ZALTMAN, G. Afinal o que os clientes querem? o que os clientes não contam e os concorrentes não sabem. Rio de Janeiro: Campus, 2003.

Artigo submetido: outubro de 2012

Artigo aprovado: dezembro de 2012 